\title{
Why is the surgical ventricular restoration operation effective for ischemic cardiomyopathy? Geometric analysis with magnetic resonance imaging of changes in regional ventricular function after surgical ventricular restoration
}

Hsi-Yu Yu, MD, PhD, ${ }^{a}$ Yih-Sharng Chen, MD, PhD, ${ }^{\text {a }}$ Wen-Yih Tseng, MD, PhD, ${ }^{\mathrm{b}, \mathrm{c}}$ Nai-Shin Chi, MD, ${ }^{\mathrm{a}}$ Chih-Hsien Wang, MD, ${ }^{\mathrm{a}}$ Shoei-Shen Wang, MD, PhD, ${ }^{\mathrm{a}}$ and Fang-Yue Lin, MD, $\mathrm{PhD}^{\mathrm{a}}$

Objective: Clinical improvement after a surgical ventricular restoration for ischemic cardiomyopathy is increasingly accepted by clinicians, but the mechanism is not completely understood.

\begin{abstract}
Methods: Ten patients with ischemic cardiomyopathy underwent detailed magnetic resonance imaging for ventricular function before and 6 weeks after surgical ventricular restoration. Surgical procedures included combinations of coronary artery bypass grafting, restrictive mitral annuloplasty, and endoventricular patch plasty. Magnetic resonance imaging analysis included quantification of global and regional systolic function. Anterior and posterior left ventricular regions were divided by an imaginary plane (C-plane) determined from anterior mitral point and both papillary roots.
\end{abstract}

Results: Global stroke volume index increased from $28.8 \pm 4.9 \mathrm{~mL} / \mathrm{m}^{2}$ to $36.5 \pm 8.6 \mathrm{~mL} / \mathrm{m}^{2}$ after surgical ventricular restoration $(P=.010)$ and seemed more related to increased posterior stroke volume index $(15.9 \pm 4.3$ $\mathrm{mL} / \mathrm{m}^{2}$ preoperatively, $21.8 \pm 3.9 \mathrm{~mL} / \mathrm{m}^{2}$ postoperatively, $\left.P=.001\right)$ than to changed anterior stroke volume in$\operatorname{dex}\left(15.9 \pm 4.4 \mathrm{~mL} / \mathrm{m}^{2}\right.$ preoperatively, $18.2 \pm 6.9 \mathrm{~mL} / \mathrm{m}^{2}$ postoperatively, $\left.P=.369\right)$. C-plane area decreased only a little in diastole $\left(37.7 \pm 8.3 \mathrm{~cm}^{2}\right.$ preoperatively, $32.9 \pm 5.9 \mathrm{~cm}^{2}$ postoperatively, $\left.P=.119\right)$ but significantly in systole $\left(31.5 \pm 9.4 \mathrm{~cm}^{2}\right.$ preoperatively, $23.7 \pm 7.6 \mathrm{~cm}^{2}$ postoperatively, $\left.P=.023\right)$. This indicates functional recovery of border zone by restrictive endoventricular patch plasty.

Conclusion: Rebuilding geometric normality by surgical ventricular restoration improves contractility of myocardium in border-zone and remote regions, resulting in increased stroke volume index from the posterior left ventricle.

Video clip is available online.

The clinical advantages of surgical ventricular restoration (SVR) for dilated ischemic cardiomyopathy have been broadly reported in previous studies, ${ }^{1,2}$ but the underlying mechanism of this improvement remains controversial. One well-known theory involves rebuilding the ventricular form $^{3}$ according to the helical ventricular myocardial band model proposed by Torrent-Guasp and colleagues. ${ }^{4}$ Another clinical study ${ }^{5}$ suggested that SVR improves mechanical intraventricular asynchrony. Laboratory analysis ${ }^{6}$ has demonstrated that SVR increases circumferential strain in the

\footnotetext{
From the Departments of Surgery ${ }^{\mathrm{a}}$ and Medical Imaging, ${ }^{\mathrm{b}}$ National Taiwan University Hospital, and the Center for Optoelectronic Biomedicine, College of Medicine, National Taiwan University, ${ }^{\mathrm{c}}$ Taipei, Taiwan.

Received for publication April 11, 2008; revisions received July 24, 2008; accepted for publication Sept 16, 2008.

Address for reprints: Fang-Yue Lin, MD, PhD, Department of Surgery, National Taiwan University Hospital, No. 7, Chung-Shan S Rd, Taipei, Taiwan 100, Republic of China (E-mail: fylin@ntuh.gov.tw).

J Thorac Cardiovasc Surg 2009;137:887-94

$0022-5223 / \$ 36.00$

Copyright (c) 2009 by The American Association for Thoracic Surgery

doi:10.1016/j.jtcvs.2008.09.037
}

remote myocardium. Because of its excellent spatial and temporal resolution, magnetic resonance imaging (MRI) is a potentially useful tool for the noninvasive evaluation of left ventricular (LV) function. This study used MRI to evaluate using MRI regional ventricular function before and after SVR in a clinical population.

\section{MATERIALS AND METHODS \\ Study Population}

Ten adult patients who had coronary artery disease and clinical heart failure with LV ejection fraction (EF) less than $40 \%$ on echocardiography together with anteroseptal scaring as evidenced by electrocardiography and marked regional akinesia or dyskinesia ${ }^{7}$ were included in this study. These patients were all scheduled to undergo surgical treatment in the near future. Coronary artery disease was diagnosed by conventional coronary angiography. Transthoracic echocardiography was applied to evaluate global and regional wall motion and the severity of mitral regurgitation. MRI was carried out to assess ventricular function and scar delineation preoperatively and at about 6 weeks postoperatively. ${ }^{8,9}$ The subjects who were recruited into the study all gave informed consent, and the study was approved by the institutional review board of the National Taiwan University Hospital.

\section{Operative Procedure}

The surgical procedure was performed through a full median sternotomy. Cardiopulmonary bypass was instituted as routine. Whether the operative procedure was performed with a beating heart ${ }^{10}$ or with cardiac arrest depended on preoperative myocardial function. For those who underwent cardiac arrest, myocardial protection was achieved with intermittent antegrade 

Abbreviations and Acronyms
$\mathrm{EF}=$ ejection fraction
EDVI $=$ end-diastolic volume index
$\mathrm{ESVI}=$ end-systolic volume index
$\mathrm{LV}=$ left ventricle
MRI = magnetic resonance imaging
MVP $=$ mitral valve prolapse
SVI $=$ stroke volume index
SVR $=$ surgical ventricular restoration

time $30 \mathrm{~ms}$, echo time $1.5 \mathrm{~ms}$, flip angle $60^{\circ}$, slice thickness $7 \mathrm{~mm}$, gap 3 $\mathrm{mm}$, field of view $370 \times 300 \mathrm{~mm}$, matrix $208 \times 256$; Figure 1). The slices were in the short-axis view and encompassed the lower third of the left atrium to the apex of the LV. Cine images at a slice location were obtained with a single breath hold of approximately 12 seconds. Approximately 12 intermittent breath holds under consistent conditions were required to complete the image acquisition. The total scan time was about 10 minutes. For scar delineation, delayed-enhancement MRI was performed over the same short-axis planes as those in TrueFISP study. The pulse sequence was inversion-recovery prepared segmented turboFLASH sequence (repetition time $1.6 \mathrm{~ms}$, echo time $1.52 \mathrm{~ms}$, flip angle $20^{\circ}$, field of view $370 \times 300 \mathrm{~mm}$, matrix size $208 \times 256$ ). The inversion time was adjusted to nullify the normal myocardium and was typically in the range of 200 to $300 \mathrm{~ms}$.

\section{Image Analysis}

The inner contour of the LV of the first time frame image was determined manually from the reconstructed 3-dimensional TrueFISP image data (Figure 1). Several points on the mitral annulus of the first time frame image were selected to determine the mitral annulus (Figure 2). An imaginary cutting plane (C-plane, Figure 2, $C$ ) was determined from the coordinates of the anterior mitral annulus and the insertion of the medial and lateral papillary muscles onto the LV. The LV was thus separated into anterior and posterior parts by this plane. Next, the corresponding coordinates of the following time frames were determined automatically with an in-house computer program. The global LV volume was determined from the volume encircled by the LV inner contour below the mitral annular plane (Figure 2). The global and regional end-diastolic volume index (EDVI), end-systolic volume index (ESVI), stroke volume index (SVI), and EF values were then determined (Figure 3; see appended video clips). The area change of the C-plane was calculated as additional information relevant to regional ventricular systolic function. In addition, the heights of the anterior and posterior LVs for each
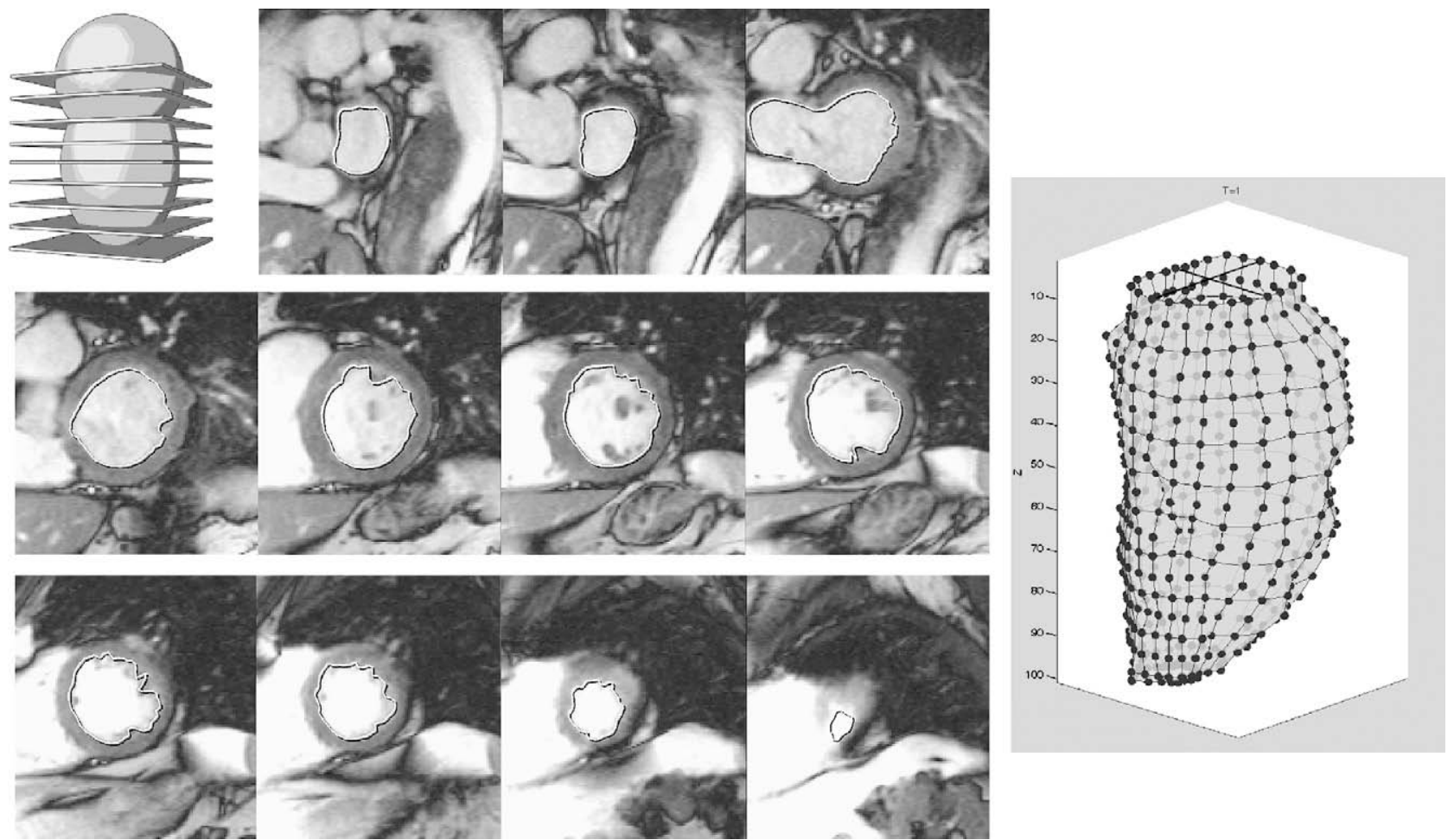

FIGURE 1. Determination of inner contour of left ventricular chamber. Cine MRI with 2-dimensional balanced steady-state free-precession sequence was acquired perpendicular to interventricular septum from left atrium to ventricle. Chamber contour during first time frame was selected by semiautomatic method; contour of following time frames was determined automatically with in-house software. 


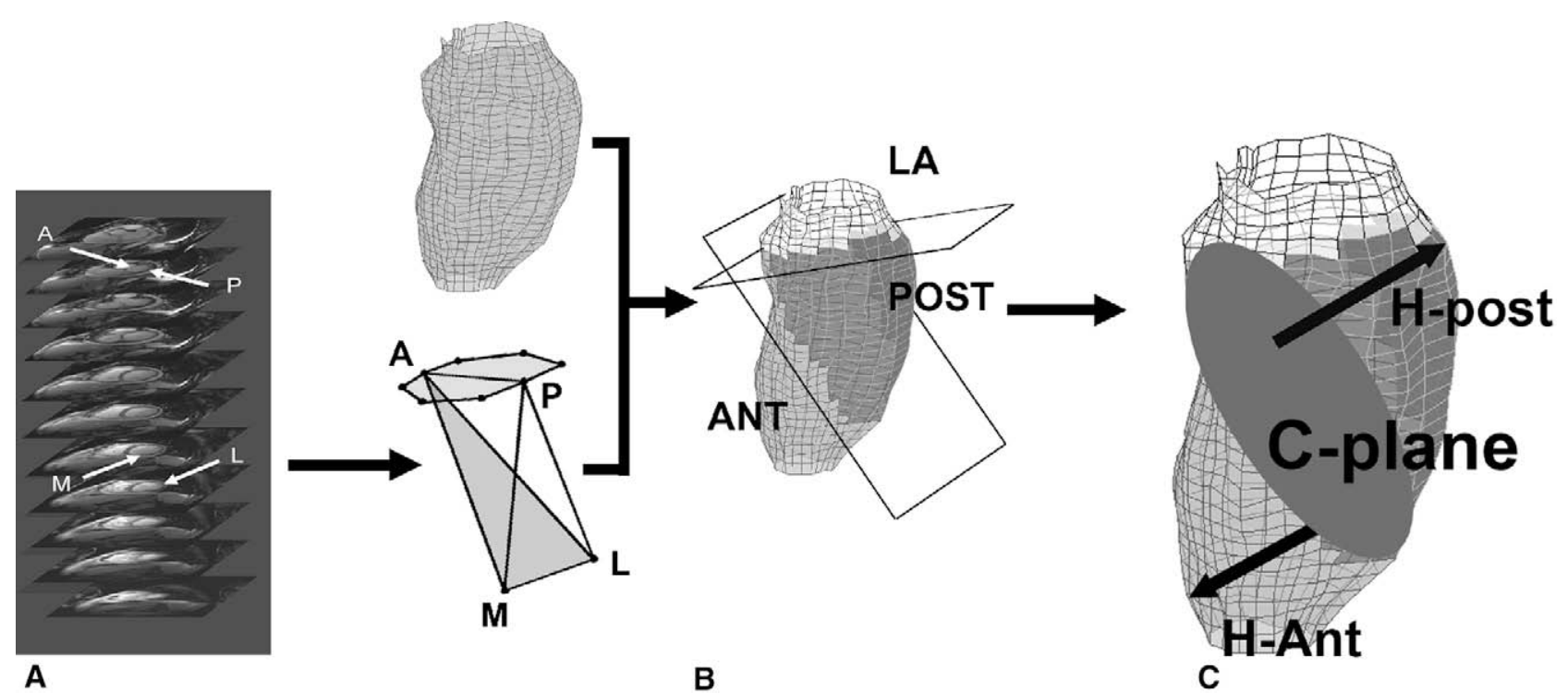

FIGURE 2. Determination of geometric parameters used in study. A, Three-dimensional locations of mitral annular plane and medial and lateral papillary muscle insertions onto ventricular wall of first time frame were determined manually. Corresponding locations during following time frame were determined automatically. Structure of mitral tetrahedron was reconstructed accordingly. B, By incorporating mitral tetrahedron and contour of left ventricular chamber, volume of left atrium ( $L A$, in white) was excluded and left ventricle was divided into anterior (ANT, in light gray) and posterior (POST, in dark gray) parts. C, Geometric parameters are illustrated as follows: heights of respective parts of left ventricle (anterior height $[H$-Ant $]$ and posterior height $[H$-Post]) were determined with highest distance from left ventricular contour points to contact surface ( $C$-plane). $A$, Anterior point of mitral annulus; $P$, posterior point of mitral annulus; $M$, medial papillary muscle root; $L$, lateral papillary muscle root.

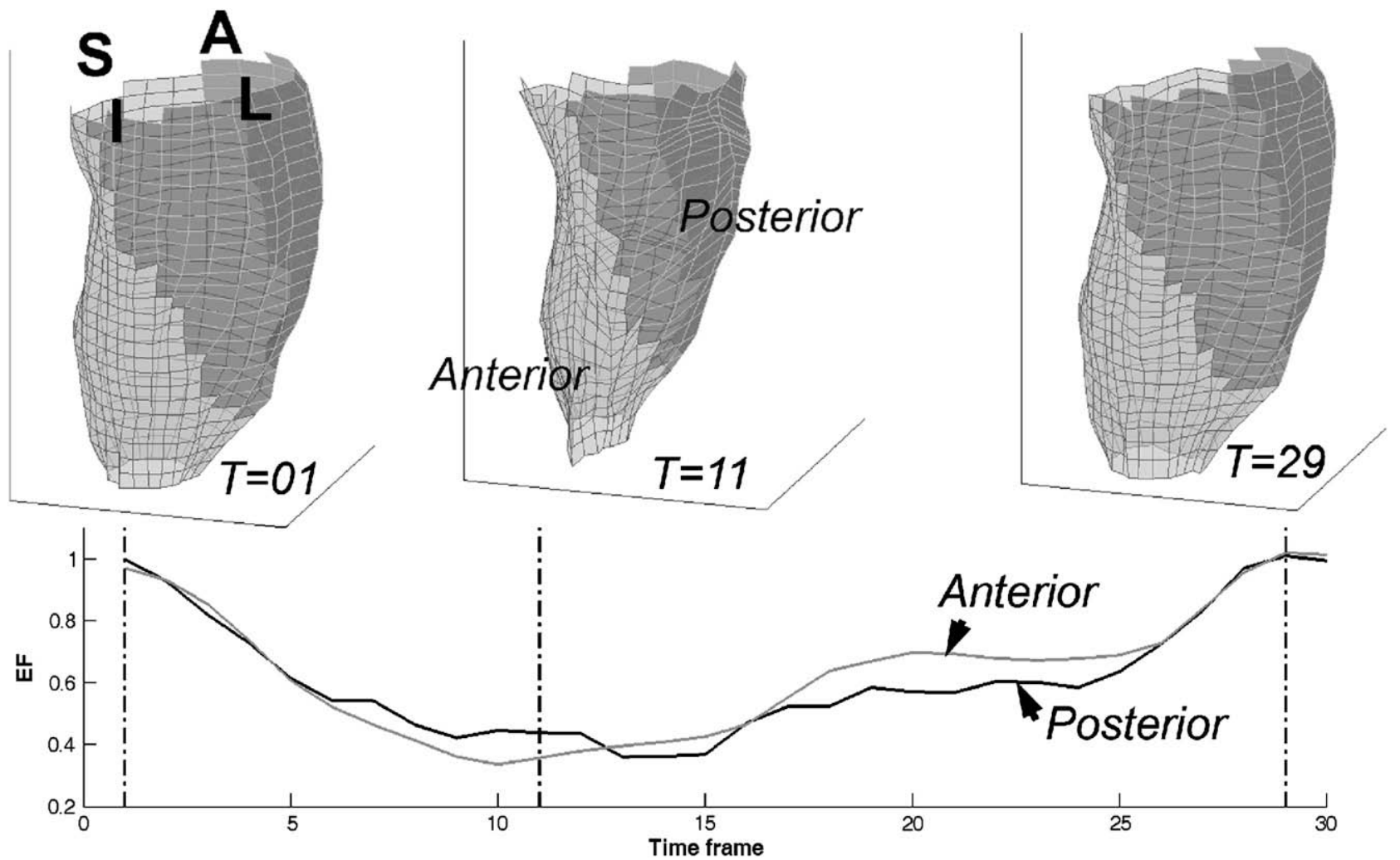

FIGURE 3. Determination of global and regional ventricular volumes. Regional ventricular volume of each time frame was determined from left ventricular contour, mitral annulus, and contact surface (C-plane) as described in Figure 2. S, Septal; $A$, anterior; $I$, inferior; $L$, lateral. 
TABLE 1. Clinical characteristics of the study group

\begin{tabular}{|c|c|}
\hline Age $(y$, mean \pm SD) & $60 \pm 8$ \\
\hline Sex (male/female ratio) & $6: 4$ \\
\hline Body surface area $\left(\mathrm{m}^{2}\right.$, mean $\left.\pm \mathrm{SD}\right)$ & $1.7 \pm 0.37$ \\
\hline Diabetes ( $\%$ affected) & $40 \%$ \\
\hline Creatinine $>1.5 \mathrm{mg} / \mathrm{dL}$ ( $\%$ affected $)$ & $40 \%$ \\
\hline $\begin{array}{l}\text { Systolic pulmonary arterial pressure }>50 \\
\mathrm{~mm} \mathrm{Hg}(\% \text { affected })\end{array}$ & $40 \%$ \\
\hline \multicolumn{2}{|l|}{$\begin{array}{l}\text { New York Heart Association functional } \\
\text { class }(\% \text { affected })\end{array}$} \\
\hline III & $70 \%$ \\
\hline IV & $30 \%$ \\
\hline Moderate to severe mitral regurgitation & $50 \%$ \\
\hline \multicolumn{2}{|l|}{ Global } \\
\hline $\operatorname{EDVI}\left(\mathrm{mL} / \mathrm{m}^{2}\right.$, mean $\left.\pm \mathrm{SD}\right)$ & $133.5 \pm 35.9$ \\
\hline $\operatorname{ESVI}\left(\mathrm{mL} / \mathrm{m}^{2}\right.$, mean $\left.\pm \mathrm{SD}\right)$ & $103.5 \pm 37.1$ \\
\hline $\mathrm{SVI}\left(\mathrm{mL} / \mathrm{m}^{2}\right.$, mean $\left.\pm \mathrm{SD}\right)$ & $28.8 \pm 4.9$ \\
\hline $\mathrm{EF}(\%$, mean $\pm \mathrm{SD})$ & $23.5 \% \pm 7.7 \%$ \\
\hline \multicolumn{2}{|l|}{ Anterior } \\
\hline $\mathrm{EDVI}\left(\mathrm{mL} / \mathrm{m}^{2}\right.$, mean $\left.\pm \mathrm{SD}\right)$ & $87.6 \pm 25.3$ \\
\hline $\operatorname{ESVI}\left(\mathrm{mL} / \mathrm{m}^{2}\right.$, mean $\left.\pm \mathrm{SD}\right)$ & $71.8 \pm 25.3$ \\
\hline $\mathrm{SVI}\left(\mathrm{mL} / \mathrm{m}^{2}\right.$, mean $\left.\pm \mathrm{SD}\right)$ & $15.9 \pm 4.4$ \\
\hline $\mathrm{EF}(\%$, mean $\pm \mathrm{SD})$ & $19.6 \% \pm 7.2 \%$ \\
\hline \multicolumn{2}{|l|}{ Posterior } \\
\hline $\operatorname{EDVI}\left(\mathrm{mL} / \mathrm{m}^{2}\right.$, mean $\left.\pm \mathrm{SD}\right)$ & $45.3 \pm 12.9$ \\
\hline $\operatorname{ESVI}\left(\mathrm{mL} / \mathrm{m}^{2}\right.$, mean $\left.\pm \mathrm{SD}\right)$ & $29.4 \pm 13.5$ \\
\hline $\mathrm{SVI}\left(\mathrm{mL} / \mathrm{m}^{2}\right.$, mean $\left.\pm \mathrm{SD}\right)$ & $15.9 \pm 4.3$ \\
\hline $\mathrm{EF}(\%$, mean $\pm \mathrm{SD})$ & $37.8 \% \pm 15.0 \%$ \\
\hline
\end{tabular}

$E D V I$, End-diastolic volume index; ESVI, end-systolic volume index; $S V I$, stroke volume index; $E F$, ejection fraction.

time frame were defined as the maximal perpendicular distance from their respective inner contours to the C-plane (Figure 2). All the image analyses and computations were performed by software developed in house with Matlab (MathWorks Inc, Natick, Mass).

\section{Statistics}

Dichotomous data were compared by $\chi 2$ test. Numeric data are presented as mean $\pm \mathrm{SD}$ and were compared between groups with either a paired or an unpaired $t$ test. All statistical analyses were performed with SPSS for Windows (SPSS Inc, Chicago, Ill).

\section{RESULTS}

The demographic data are presented in Table 1. Generally, the study group included a high percentage of patients with diabetes and those with a New York Heart Association functional class IV condition. The average number of coronary bypass grafts was $3.0 \pm 1.3$. Restrictive annuloplasty was performed in 5 patients $(50 \%)$, all of whom had shown significant preoperative mitral regurgitation. Five patients $(50 \%)$ underwent intra-aortic balloon pump insertion after the operation. All patients survived the operation.

Analysis of the MRI at about 6 postoperative weeks revealed improved global LV systolic function after the operation (Figure 4). Global EDVI decreased from $133.5 \pm 35.9$ $\mathrm{mL} / \mathrm{m}^{2}$ preoperatively to $92.4 \pm 22.4 \mathrm{~mL} / \mathrm{m}^{2}$ postoperatively $(P=.003)$. ESVI decreased from $103.5 \pm 37.1 \mathrm{~mL} /$ $\mathrm{m}^{2}$ to $54.7 \pm 25.9 \mathrm{~mL} / \mathrm{m}^{2}(P=.002)$. SVI increased from $28.8 \pm 4.9 \mathrm{~mL} / \mathrm{m}^{2}$ to $36.5 \pm 8.6 \mathrm{~mL} / \mathrm{m}^{2}(P=.010)$. EF increased from $23.6 \% \pm 7.7 \%$ to $43 \% \pm 14.7 \%(P=.001)$. Global EF increased from $23.6 \% \pm 7.7 \%$ to $43 \% \pm 14.7 \%$ $(P=.001)$.

For the anterior LV, which involved the endoventricular patch-related region, both the EDVI and ESVI decreased (for EDVI $87.6 \pm 25.3 \mathrm{~mL} / \mathrm{m}^{2}$ preoperatively to $50.6 \pm$ $15.9 \mathrm{~mL} / \mathrm{m}^{2}$ postoperatively, $P=.001$, for ESVI $71.8 \pm$ $25.3 \mathrm{~mL} / \mathrm{m}^{2}$ preoperatively to $31.8 \pm 15.3 \mathrm{~mL} / \mathrm{m}^{2}$ postoperatively, $P=.001$ ), but SVI did not change significantly $\left(15.9 \pm 4.4 \mathrm{~mL} / \mathrm{m}^{2}\right.$ preoperatively to $18.2 \pm 6.9 \mathrm{~mL} / \mathrm{m}^{2}$ postoperatively, $P=.369$ ). EF increased, however, from $19.6 \% \pm 7.2 \%$ preoperatively to $38.9 \% \pm 17.5 \%$ postoperatively $(P=.003)$.

For the posterior LV, the EDVI did not change significantly $\left(45.3 \pm 12.9 \mathrm{~mL} / \mathrm{m}^{2}\right.$ preoperatively to $42.9 \pm 12.9$ $\mathrm{mL} / \mathrm{m}^{2}$ postoperatively, $\left.P=.555\right)$, but the ESVI did decrease significantly $\left(29.4 \pm 13.5 \mathrm{~mL} / \mathrm{m}^{2}\right.$ preoperatively to $21.2 \pm 11.8 \mathrm{~mL} / \mathrm{m}^{2}$ postoperatively, $P=.062$ ), which resulted in increased SVI and EF postoperatively (for SVI $15.9 \pm 4.3 \mathrm{~mL} / \mathrm{m}^{2}$ preoperatively to $21.8 \pm 3.9 \mathrm{~mL} / \mathrm{m}^{2}$ postoperatively, $P=.001$, for EF $37.8 \pm 15.0 \%$ preoperatively to $53.2 \pm 12.9 \%$ postoperatively, $P=.004$ ).

Analysis of the change in C-plane area (Table 2) reveled that the diastolic area decreased slightly from $37.7 \pm 8.3 \mathrm{~cm}^{2}$ preoperatively to $32.9 \pm 5.9 \mathrm{~cm}^{2}$ postoperatively $(P=$ .119), whereas the systolic area decreased even more from $31.5 \pm 9.4 \mathrm{~cm}^{2}$ preoperatively to $23.7 \pm 7.6 \mathrm{~cm}^{2}$ postoperatively $(P=.023)$. The area ratios between systole and diastole were $0.83 \pm 0.10$ preoperatively and $0.70 \pm 0.11$ postoperatively $(P=.011)$, a statistically significant change.

Interestingly, the diastolic and systolic heights of the anterior LV (Figure 2) decreased after the operation, but the shortening ratio was unchanged $(0.95 \pm 0.05$ preoperatively and $0.97 \pm 0.17$ postoperatively, $P=.802$ ). This may be explained by the compound effect of the scarred myocardium and the prosthetic patch in the anterior LV. Paradoxically, the diastolic height of the posterior LV (Figure 2) increased after the operation $(3.5 \pm 0.59 \mathrm{~cm}$ preoperatively to $3.7 \pm$ $0.45 \mathrm{~cm}$ postoperatively, $P=.039$ ), whereas the systolic height of the posterior LV did not change $(3.0 \pm 0.68 \mathrm{~cm}$ preoperatively to $3.0 \pm 0.58 \mathrm{~cm}$ postoperatively, $P=$ $.910)$. This resulted in a trend toward an improved shortening ratio $(0.85 \pm 0.08$ preoperatively to $0.81 \pm 0.10$ postoperatively, $P=.133$ ), although this trend was not significant.

Cases were further divided into patients with and without mitral valve plasty (MVP, $\mathrm{n}=5$ per group; Figure 5 ). Patients with MVP had a higher global EDVI, a higher ESVI, and a comparable SVI relative to patients without MVP, indicating a more dilated LV and less effective SVI for the patients with MVP. After SVR, similar trends towards decreased global EDVI, decreased global ESVI, increased global SVI, decreased C-plane changing ratio, 

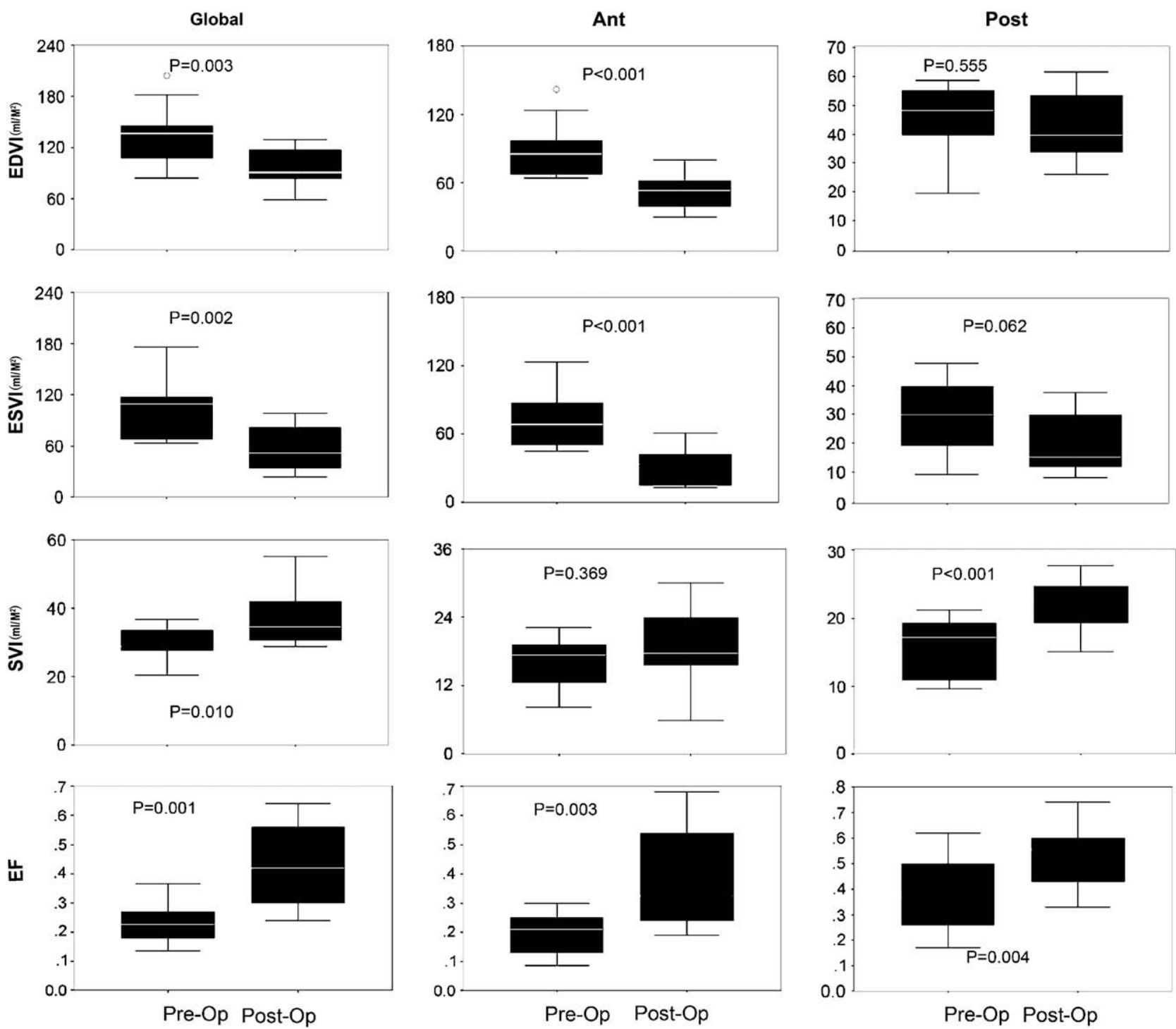

FIGURE 4. Global and regional (anterior $[A n t]$ and posterior $[$ Post $]$ ) ventricular functions before (Pre-Op) and after $(P o s t-O p)$ surgical ventricular restoration. Global systolic function improved postoperatively. For anterior left ventricle, end-diastolic volume index (EDVI) and end-systolic volume index $(E S V I)$ decreased after operation, but stroke volume index (SVI) did not change significantly. For posterior left ventricle, end-diastolic volume index was relatively unchanged after operation, but end-systolic volume index decreased. Stroke volume index and ejection fraction $(E F)$ therefore increased.

unchanged anterior SVI, and increased posterior SVI were seen in patients with and without MVP. Interestingly, the posterior EDVI and ESVI were markedly higher preoperatively in patients with MVP than in those without, but these values decreased and became more comparable between the two groups after the operation. This suggests that restrictive mitral annuloplasty may have an effect when rebuilding normal geometry ${ }^{14}$ in patients with functional mitral regurgitation undergoing SVR and that this occurs by increasing the contractility of the dilated posterior LV.

\section{DISCUSSION}

This study showed that the increase in global SVI after SVR is contributed to mainly by the posterior LV rather than the anterior LV. The endoventricular patch exerts a restrictive effect on previously dilated border-zone myocardium at the C-plane, which rebuilds normal geometry, facilitates reverse remodeling, and results in improved systolic performance. This is shown by the postoperatively increased area changing ratio of the $\mathrm{C}$-plane.

Unlike previous studies, in which the LV was regionalized by horizontal planes, this study used an oblique imaginary plane determined by the anterior mitral annulus point and both papillary roots (C-plane, Figure 2 ). This imaginary cutting plane has been used in previous studies ${ }^{15,16}$ of ischemic functional mitral regurgitation, in which a structure named the mitral tetrahedron was located behind this plane and positioned in the posterior LV. The advantages of using 
TABLE 2. Geometric parameters before and after surgical ventricular restoration

\begin{tabular}{lccr}
\hline \multicolumn{1}{c}{ Parameter } & Preoperative & Postoperative & $P$ value \\
\hline $\begin{array}{l}\text { C-plane area, diastole } \\
\quad\left(\mathrm{cm}^{2}, \text { mean } \pm \mathrm{SD}\right)\end{array}$ & $37.7 \pm 8.3$ & $32.9 \pm 5.9$ & .119 \\
$\begin{array}{l}\text { C-plane area, systole } \\
\quad\left(\mathrm{cm}^{2}, \text { mean } \pm \mathrm{SD}\right)\end{array}$ & $31.5 \pm 9.4$ & $23.7 \pm 7.6$ & .023 \\
Changing ratio (mean $\pm \mathrm{SD})$ & $0.83 \pm 0.10$ & $0.70 \pm 0.11$ & .011 \\
Anterior & & & \\
$\quad$ Height, diastole $(\mathrm{cm})$ & $5.5 \pm 0.48$ & $3.9 \pm 0.66$ & 0.001 \\
Height, systole $(\mathrm{cm})$ & $5.3 \pm 0.6$ & $3.7 \pm 0.85$ & $<.001$ \\
$\quad$ Changing ratio* & $0.95 \pm 0.05$ & $0.97 \pm 0.17$ & .802 \\
Posterior & & & \\
$\quad$ Height, diastole $(\mathrm{cm})$ & $3.5 \pm 0.59$ & $3.7 \pm 0.45$ & .039 \\
Height, systole $(\mathrm{cm})$ & $3.0 \pm 0.68$ & $3.0 \pm 0.58$ & .910 \\
$\quad$ Changing ratio* & $0.85 \pm 0.08$ & $0.81 \pm 0.10$ & .133 \\
\hline *Changing ratio is ratio of systolic value to diastolic value. &
\end{tabular}

this plane in this study were as follows. First, the three points determining the C-plane (anterior mitral point, medial and lateral papillary roots) can be accurately located and traced in the reconstructed 3-dimensional MRI data, allowing precise partitioning of the LV during the whole cardiac cycle (Figure 3). Second, the endoventricular patch is entirely located in the anterior LV, and thus the posterior LV can be viewed as a remote region. Third, the oblique C-plane is quite useful for scar delineation when there are anterior infarctions. The last point may not be operative if any restoration is carried out on lateral or inferior scars. In these cases, although the principles may be correct for the MRI analysis, the use of a different plane may be more helpful when carrying out restoration on different areas.

A previous animal study ${ }^{9}$ has already demonstrated that the short-axis diameter decreases during both diastole and systole after SVR, whereas the shortening distance is unchanged. Our results are in accordance with this finding. We found the height of the anterior LV changing ratio to be unchanged from before to after SVR, which suggests that there is relatively little contractile improvement in the anterior LV, possibly because of the heavily scarred myocardium in this region. The paradoxic increase in diastolic height of the anterior LV after SVR can be explained by the increased global SVI and the decreased global ESVI after SVR, which cause the relatively compliant posterior LV to dilate to accommodate the excessive SVI. This finding implies that to achieve an adequate increase in SVI after SVR without excessive increase in the LV filling pressure, the remote myocardium plays a critical role and must have a potentially favorable Frank-Starling relationship. ${ }^{17}$ Earlier research by Donato and associates ${ }^{18}$ suggested that for cases with LV anterior aneurysm, the preoperative presence of systolic negative curvature at the junction between the myocardium and the aneurysm is a good prognostic sign for LV functional recovery. Probably the preoperative presence of any systolic negative curvature (by 2-dimensional imaging) or negative tension (by 3-dimensional imaging) at the junction between remote and scarred myocardium identified by detailed MRI analysis also provides a good prognostic indicator for SVR cases.

Previous finite-element analysis ${ }^{8}$ has demonstrated that border-zone myofiber stress would decrease and EF increase at the expense of decreased global SVI after SVR if the contractile properties of the ventricular muscle were to remain unchanged. Because the SVI did increase after the operation in this other studies, ${ }^{9}$ however, it is evident that the myofiber contractile properties improve after SVR. Whether this improvement is related to the restricting effect of the endoventricular patch, to the improvement in the geometric shape of the $\mathrm{LV}$, or to the effect of revascularization still needs to be evaluated.

An earlier study ${ }^{19}$ has demonstrated that the prevention of any expansion of the border-zone myocardium after transmural myocardial infarction is able to prevent late heart failure. Similar to the effect of commercial ventricular restraint devices ${ }^{20}$ the endoventricular patch in SVR provides an internal restraining effect that maintains the radial curvature and decreases the stress in the border-zone region. Earlier studies ${ }^{21,22}$ have demonstrated that the decrease of intraventricular tension resulting from $\mathrm{LV}$ assist device placement or relief of aortic stenosis is able to induce changes in the biologic markers. This is indicative of a reverse remodeling process. Our study showed that C-plane contractility improves significantly immediately after SVR. It is possible that reverse remodeling may happen in the border zone and induce further improvement in myocardial function.

The group with MVP showed higher preoperative EDVI and ESVI values than did the group without MVP (Figure 5), indicating that a relatively floppy LV was present among the patients with MVP. The EDVI and ESVI values of the posterior LV were relatively unchanged postoperatively among the patients without, but the EDVI of the posterior LV was slightly decreased and the ESVI of the posterior LV was markedly decreased postoperatively among patients with MVP. This finding indicates that restrictive mitral annuloplasty may exert an additional remodeling effect on patients undergoing SVR who have associated functional mitral regurgitation. This effect would seem to contribute to the restoration of posterior LV shape and to improve functionality toward normality.

Cardiac MRI has been applied in many ways to the study of SVR ${ }^{23-27}$ including the delineation of scar extent, ${ }^{28}$ calculation of ventricular asynergic area, ${ }^{23}$ assessment of regional myocardial strain, ${ }^{6,25,27}$ determination of global myocardial fiber orientation, ${ }^{25}$ and analysis of ventricular torsional mechanics. ${ }^{26}$ Our study provides an additional approach that is able to evaluate global and regional ventricular volume changes. To calculate the ventricular volume change during the entire cardiac cycle accurately, the vertical motion of the 

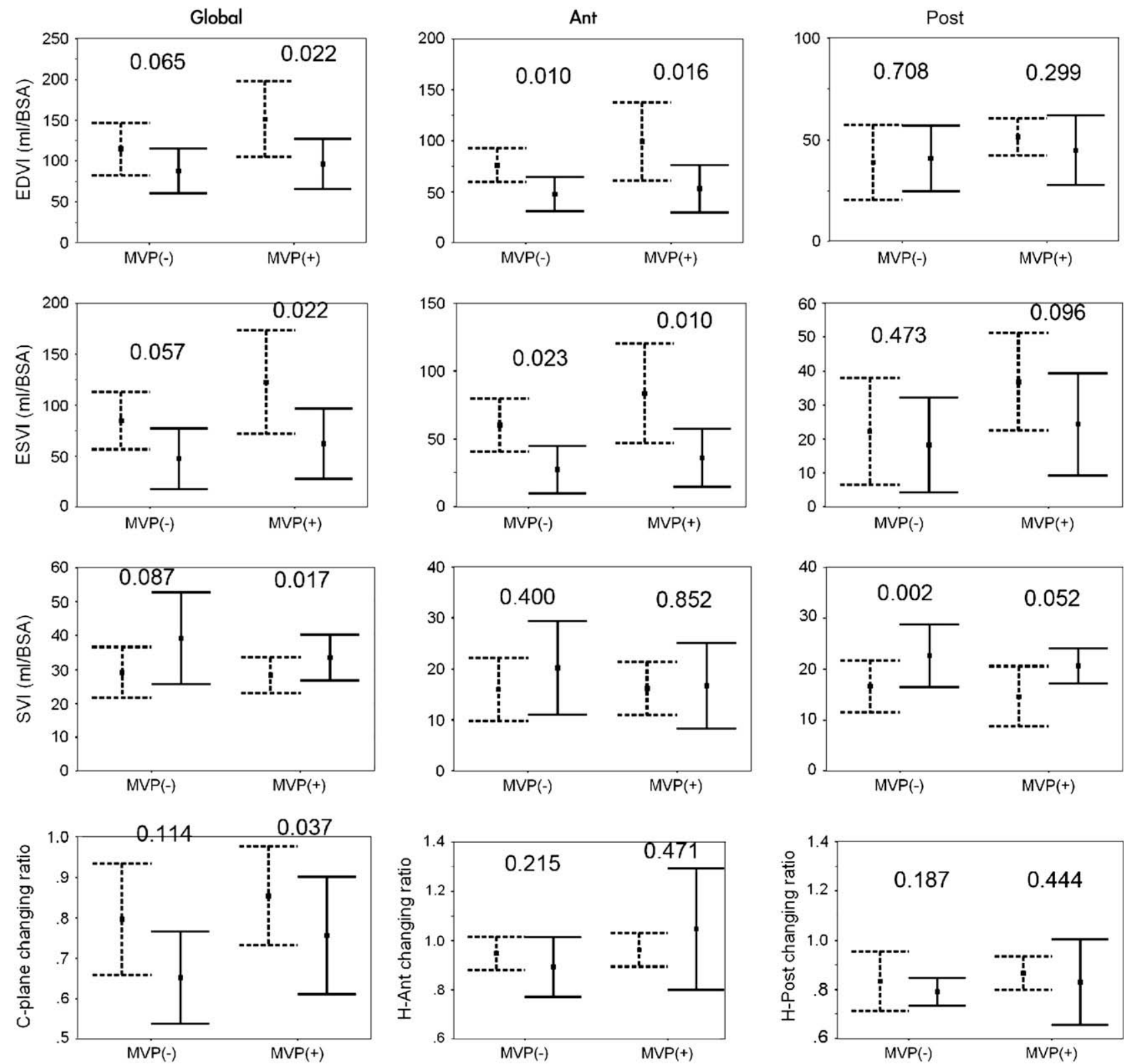

FIGURE 5. Trends in change in volume index values before and after surgical ventricular restoration for patients without mitral valve prolapse $[M V P(-)$, $\mathrm{n}=5]$ and patients with mitral valve prolapse $[M V P(+), \mathrm{n}=5] . P$ values for differences between preoperative results (dashed lines) and postoperative results (solid lines) are shown. Similar trend, including decreased global end-diastolic volume index (EDVI), decreased global end-systolic volume index (ESVI), increased global stroke volume index (SVI), decreased C-plane changing ratio, unchanged anterior (Ant) stroke volume index, and increased posterior (Post) stroke volume index, was seen for patients both with and without mitral valve prolapse.

mitral annulus must be taken into consideration. Our study determined the mitral annular plane for each time frame from a reconstructed 3-dimensional data set with an automatic method; this approach has rarely been used in previous studies. With this approach, it is possible to precisely distinguish the LV volume from the left atrial volume.

When this approach is compared with the MRI tagging technique used in previous animal studies, ${ }^{6,26}$ our protocol is less time-consuming but still provides good spatial and temporal resolution. It therefore can be considered a safe and useful study tool for relatively ill patients with ischemic cardiomyopathy, such as those enrolled in our study.

\section{Limitations}

Our study focused mainly on the geometric changes after SVR. Preoperative geometric changes, however, may lead to the structural and biochemical derangement of the myocytes, which will worsen cardiac function and increase neurohormonal activation. Whether the benefit of SVR comes directly from a mechanical factor (decreased circumferential 
stress during systole) or is mediated through other biologic factors remains to be elucidated in further studies. Our studies were carried out in approximately 6 weeks, and according to some earlier studies ${ }^{29}$ further myocardial structural changes may happen after this time. It is therefore quite possible that further improvements might be expected after 6 weeks. The patients enrolled in our study all had ischemic heart disease and an anteroseptal infarct. Whether these findings can also be applied to cases of LV with inferior or posterior aneurysm or, even more importantly, to dilated cardiomyopathy remains a topic for further study.

The estimation of the stroke volume by the LV end-diastolic and end-systolic volumes will be inaccurate in the presence of mitral regurgitation. In a future study, it should be possible to estimate a true effective SVI by using the stroke volume of the right ventricle if mitral regurgitaton is present and tricuspid regurgitation does not exist. Another MRI protocol allowing flow estimation, such as phasecontrast sequence, might also be useful when evaluating effective stroke volume. Finally, it is possible that the postoperative medication used by these patients had an effect on the reverse remodeling process during the long-term followup. We did not study the effect of postoperative medication in our short-term study.

\section{CONCLUSION}

In conclusion, our study demonstrates that the increase in SVI after SVR originates from an increase in SVI of the posterior LV. An endoventricular patch on the anterior LV would seem to exert a restrictive effect on the previously dilated border-zone myocardium, improving the contractility of myocardium in the border zone and also in remote regions.

\section{References}

1. Dor V, Di Donato M, Sabatier M, Montiglio F, Civaia F. Left ventricular reconstruction by endoventricular circular patch plasty repair: a 17-year experience. Semin Thorac Cardiovasc Surg. 2001;13:435-47.

2. Menicanti L, Castelvecchio S, Ranucci M, Frigiola A, Santambrogio C, de Vincentiis C, et al. Surgical therapy for ischemic heart failure: single-center experience with surgical anterior ventricular restoration. J Thorac Cardiovasc Surg. 2007;134:433-41.

3. Buckberg GD. RESTORE Group. Form versus disease: optimizing geometry during ventricular restoration. Eur J Cardiothorac Surg. 2006;29(Suppl 1):S238-44.

4. Torrent-Guasp F, Buckberg GD, Clemente C, Cox JL, Coghlan HC, Gharib M. The structure and function of the helical heart and its buttress wrapping. I. The normal macroscopic structure of the heart. Semin Thorac Cardiovasc Surg. 2001;13:301-19.

5. Di Donato M, Toso A, Dor V, Sabatier M, Barletta G, Menicanti L, et al. Surgical ventricular restoration improves mechanical intraventricular dyssynchrony in ischemic cardiomyopathy. Circulation. 2004;109:2536-43.

6. Zhang P, Guccione JM, Nicholas SI, Walker JC, Crawford PC, Shamal A, et al. Endoventricular patch plasty for dyskinetic anteroapical left ventricular aneurysm increases systolic circumferential shortening in sheep. J Thorac Cardiovasc Surg. 2007; 134:1017-24.

7. Di Donato M, Sabatier M, Dor V, Toso A, Maioli M, Fantini F. Akinetic versus dyskinetic postinfarction scar: relation to surgical outcome in patients undergoing endoventricular circular patch plasty repair. J Am Coll Cardiol. 1997;29:1569-75.
8. Dang AB, Guccione JM, Zhang P, Wallace AW, Gorman RC, Gorman JH 3rd, et al. Effect of ventricular size and patch stiffness in surgical anterior ventricular restoration: a finite element model study. Ann Thorac Surg. 2005;79: 185-93.

9. Zhang P, Guccione JM, Nicholas SI, Walker JC, Crawford PC, Shamal A, et al. Left ventricular volume and function after endoventricular patch plasty for dyskinetic anteroapical left ventricular aneurysm in sheep. J Thorac Cardiovasc Surg. 2005;130:1032-8.

10. Athanasuleas C, Siler W, Buckberg G. Myocardial protection during surgical ventricular restoration. Eur J Cardiothorac Surg. 2006;29(Suppl 1):S231-7.

11. Dor V, Montiglio F, Sabatier M, Coste P, Barletta G, Di Donato M, et al. Left ventricular shape changes induced by aneurysmectomy with endoventricular circular patch plasty reconstruction. Eur Heart J. 1994;15:1063-9.

12. Lee KK, Wang CH, Yu HY, Chen YS. Hand-made sizing balloon in surgical ventricular restoration. Interact Cardiovasc Thorac Surg. 2006;5:301-2.

13. Tseng WY, Liao TY, Wang JL. Normal systolic and diastolic functions of the left ventricle and left atrium by cine magnetic resonance imaging. J Cardiovasc Magn Reson. 2002;4:443-57.

14. Buckberg GD, Athanasuleas CL. Seeing congestive heart failure with the eyes of the mind: a surgical view. Semin Thorac Cardiovasc Surg. 2001;13:431-4.

15. Yu HY, Su MY, Chen YS, Lin FY, Tseng WY. Mitral tetrahedron as a geometrical surrogate for chronic ischemic mitral regurgitation. Am J Physiol Heart Circ Physiol. 2005;289:H1218-25.

16. Yu HY, Su MY, Liao TY, Peng HH, Lin FY, Tseng WY. Functional mitral regurgitation in chronic ischemic coronary artery disease: analysis of geometric alterations of mitral apparatus with magnetic resonance imaging. $J$ Thorac Cardiovasc Surg. 2004;128:543-51.

17. Tulner SA, Steendijk P, Klautz RJ, Bax JJ, Schalij MJ, van der Wall EE, et al. Surgical ventricular restoration in patients with ischemic dilated cardiomyopathy: evaluation of systolic and diastolic ventricular function, wall stress, dyssynchrony, and mechanical efficiency by pressure-volume loops. J Thorac Cardiovasc Surg. 2006;132:610-20.

18. Di Donato M, Sabatier M, Toso A, Barletta G, Baroni M, Dor V, et al. Regional myocardial performance of non-ischaemic zones remote from anterior wall left ventricular aneurysm. Effects of aneurysmectomy. Eur Heart J. 1995; 16:1285-92.

19. Jackson BM, Gorman JH, Moainie SL, Guy TS, Narula N, Narula J, et al. Extension of borderzone myocardium in postinfarction dilated cardiomyopathy. J Am Coll Cardiol. 2002;40:1160-71.

20. Blom AS, Pilla JJ, Arkles J, Dougherty L, Ryan LP, Gorman JH 3rd, et al. Ventricular restraint prevents infarct expansion and improves borderzone function after myocardial infarction: a study using magnetic resonance imaging, threedimensional surface modeling, and myocardial tagging. Ann Thorac Surg. 2007;84:2004-10.

21. Wohlschlaeger J, Schmitz KJ, Schmid C, Schmid KW, Keul P, Takeda A, et al. Reverse remodeling following insertion of left ventricular assist devices (LVAD): a review of the morphological and molecular changes. Cardiovasc Res. 2005;68:376-86.

22. Walther T, Schubert A, Wustmann T, Falk V, Walther C, Doll N, et al. Reverse remodeling of cardiac collagen protein expression after surgical therapy for experimental aortic stenosis. J Heart Valve Dis. 2006;15:651-6.

23. Lloyd SG, Buckberg GD. Use of cardiac magnetic resonance imaging in surgical ventricular restoration. Eur J Cardiothorac Surg. 2006;29(Suppl 1): S216-24.

24. Buckberg GD, Mahajan A, Jung B, Markl M, Hennig J, Ballester-Rodes M. MRI myocardial motion and fiber tracking: a confirmation of knowledge from different imaging modalities. Eur J Cardiothorac Surg. 2006;29(Suppl 1): S165-77.

25. Jung BA, Kreher BW, Markl M, Hennig J. Visualization of tissue velocity data from cardiac wall motion measurements with myocardial fiber tracking: principles and implications for cardiac fiber structures. Eur J Cardiothorac Surg. 2006; 29(Suppl 1):S158-64.

26. Setser RM, Smedira NG, Lieber ML, Sabo ED, White RD. Left ventricular torsional mechanics after left ventricular reconstruction surgery for ischemic cardiomyopathy. J Thorac Cardiovasc Surg. 2007;134:888-96.

27. Buckberg GD, Schelbert H, Mahajan A. Cardiac motion and fiber shortening: the whole and its parts. Eur J Cardiothorac Surg. 2006;29(Suppl 1):S145-9.

28. Isbell DC, Kramer CM. Magnetic resonance for the assessment of myocardial viability. Curr Opin Cardiol. 2006;21:469-72.

29. Caulfield JB, Janicki JS. Structure and function of myocardial fibrillar collagen. Technol Health Care. 1997;5:95-113. 